\title{
FERIDAS ABERTAS: \\ NARCISISMO DAS PEQUENAS DifERENÇAS, REPETIÇÃo E MEMÓRIA
}

Lucas de Oliveira Alves ${ }^{1}$

\section{RESUMO}

Esse artigo propõe-se a refletir sobre o conceito freudiano de narcisismo das pequenas diferenças, pensado a partir da amarração dos registros lacanianos de real, simbólico e imaginário, e sua incidência nas relações sociais brasileiras em diferentes tempos. Parte-se da discussão do conceito na teoria psicanalítica, para na sequência, em diálogo com teóricos como Walter Benjamin e Giorgio Agamben, refletir sobre a repetição, assim como sobre relevância da memória para a percepção de nossos sintomas sociais. Discorre-se sobre como alguns discursos apropriam-se da imagem das diferenças para perpetrar e resgatar lógicas de opressão, desigualdade e sobre o modo como o resgate da memória, articulada a uma possibilidade de elaboração, pode ensejar diferentes modos de se relacionar na pólis e lidar com as diferenças.

PaLAVRAS-ChaVe: Narcisismo. Diferença. Repetição. Memória. Sintoma.

\footnotetext{
${ }^{1}$ Graduado em Psicologia pela Unisul (Universidade do Sul de Santa Catarina). Mestrando em Psicologia Social e Cultura na UFSC (Universidade Federal de Santa Catarina). Psicanalista em formação pela Maiêutica - Florianópolis. Endereço: Programa de Pós-Graduação em Psicologia. Universidade Federal de Santa Catarina - UFSC. Campus Universitário - Trindade - CEP 88.040-970 - Florianópolis - Santa Catarina - Brasil. Telefone: (48) 99615-5984 E-mail: lukass.oliveira@hotmail.com ORCID: https://orcid.org/0000-0002-7226-9960
} 


\section{INTRODUÇÃO}

Freud (1921) em "Psicologia das massas e análise do eu", afirma que a psicologia individual é uma psicologia social. A sentença do psicanalista nos abre para o universo de desdobramentos que alguns de seus conceitos clínicos tiveram em discussões e reflexões sociais e políticas. Atenta às reverberações e articulações entre psiquismo e cultura, a psicanálise freudiana tencionou os limites instituídos na época entre individual e social, enfatizando a singularidade do laço social.

Podemos refletir, ao modo como nos aponta o filósofo Walter Benjamin no livro das Passagens, que os conceitos freudianos estabelecem limiares. O sentido de limiar, em alemão (schwelle), diferencia-se da fronteira. A fronteira é uma divisão, aquilo que aparta, já o limiar compreende o que estando entre dois espaços, permite um trânsito, excedendo espaços outrora circunscritos (GAGNEBIN, 2014). Nesse sentido, Betty Fuks (2016), em sua resenha do livro "Litorais da Psicanálise”, comenta: “(...) Freud sempre priorizou a experiência do inconsciente como motor das incursões que precisou fazer a outros campos do saber. Lacan nomeou essa condição de limiar do inconsciente de extimidade" (FUKS, 2016 p. 110).

A extimidade, aquilo que é paradoxalmente íntimo e externo, evidencia tanto o caráter liminar da psicanálise, quanto dos conceitos que pretendemos operacionalizar nesse artigo: o narcisismo das pequenas diferenças, a repetição e a memória. $O$ narcisismo das pequenas diferenças, conceito sobre o qual nos debruçaremos mais atentamente, emerge na literatura psicanalítica como desdobramento do conceitochave de narcisismo.

Freud, partindo do mito grego de Narciso, nos apresenta o narcisismo como constituinte dos sujeitos, operando como um vetor das relações entre o eu e o outro. Refere-se a relações de amor, ódio e ignorância como nos aponta Lacan (195354/1986), tecendo aquilo que o psicanalista francês denominou de imaginário em suas intersecções com o simbólico e com o real.

Atento às vicissitudes da pulsão na clínica e na polis, Freud passa a analisar as manifestações do narcisismo para além do âmbito individual, perscrutando suas ressonâncias nos grupos. Em diálogo com as ciências sociais e, mais detidamente, em "Psicologia das massas" (1921), com o sociólogo Gustave Le Bom, Freud amplia os estudos sobre o narcisismo, permitindo-nos operacionalizar seu conceito em leituras 
dos fenômenos extramuros e ofertando-nos passagens de mão dupla para escutar o que é clínico de forma indissociável do social.

Lacan (1953-54/1986), no esteio das discussões freudianas, passa a teorizar sobre um sujeito do inconsciente estruturado nos três registros. O imaginário é, por excelência, o registro do narcisismo, das relações especulares e constituintes do eu e do outro, contudo, só podemos compreendê-lo em articulação ao simbólico e ao real, pois somente pela incidência do simbólico e pela persistência do real, faz-se possível escutar e refletir sobre o narcisismo nas subjetividades e nas relações.

Tendo esta breve introdução em vista, temos como objetivo central nesse artigo ensejar reflexões sobre o narcisismo das pequenas diferenças na sociedade brasileira. Para alcançá-lo, tencionamos apresentar aspectos teóricos do conceito em Freud e Lacan, percorrendo o caminho da formulação da noção de narcisismo à noção do narcisismo das pequenas diferenças. Ato contínuo, abordaremos o conceito de repetição em sua relação com a memória, procurando refletir sobre as repetições que ocorrem no âmbito das relações sociais e políticas brasileiras. Dessa forma, iremos enfatizar a relevância da memória para os processos de elaboração.

O método seguirá o princípio da atenção flutuante. Buscaremos estabelecer uma leitura e uma escuta guiada pelos significantes que emergem e bordeiam a realidade sociopolítica do nosso país, em seus recortes, camadas e antagonismos. Não se trata propriamente de uma atividade interpretativa, mas de uma reflexão que possa nos fazer interrogar, pela operacionalização dos conceitos, sobre as marcas que atravessam nossa história, sobre nossas repetições e, na linha de pensamento de autores como Walter Benjamin (1987) e Giorgio Agamben (2009), sobre os tempos heterogêneos que constituem nosso presente.

Destacamos ainda que o método se embasa na noção lacaniana (1968-69/2008) do amor às verdades, compreendendo a verdade como uma meia-verdade, verdade não-toda da realidade, constituída por brechas. Essas rachaduras nos permitem ver o seu caráter ficcional e enseja-nos o desejo, por nossa condição de castrados, de ficcionar realidades.

\section{Do Narcisismo Do Bebê Ao Narcisismo Das MASSAS}

"Vossa Majestade, o bebê", célebre frase de Freud cuja dimensão nos ambienta em uma esfera mitológica da teoria psicanalítica, indica-nos o estatuto primordial do narcisismo e de sua relação com a constituição do eu. Freud (1914/2010) aponta que 
o narcisismo do bebê está em uma relação de dependência com o investimento libidinal das figuras parentais. A libidinização parental ocorre antes mesmo que a criança possa se perceber como possuidora de um corpo e, por conseguinte, que possa se enunciar como eu. Nesse sentido, Freud (1914/2010, p.13) afirma que "uma unidade comparável ao eu não existe na origem, não está presente desde o início no indivíduo, e o eu tem de se desenvolver. As pulsões autoeróticas, ao contrário, estão lá desde o início".

No texto "O estádio do espelho como formador da função do eu" e em seminários posteriores, Lacan (1949/1998, 1956-57/1995) nos falará da virada que possibilita a assunção da função do eu. É por meio da visão de sua imagem refletida e da percepção do outro que se afasta que o infans se perceberá como portador de uma imagem corporal independente. Como o desvelamento dessa diferença/separação é inelutavelmente marcado pela percepção desse outro, seja a corporeidade dos pais ou o próprio reflexo da criança no espelho, há em cena uma dimensão da alienação alienação à imagem (imaginário, pelo outro) articulada a uma alienação no universo da linguagem (simbólico, pelo desejo do Outro).

Freud (1914/2010) nos indica que em dado momento, posterior ao que ele denomina de narcisismo primário - período em que a libido ainda está toda investida no eu - ocorre um investimento libidinal em uma exterioridade, marcando a passagem do Eu ideal para o Ideal de eu. O eu, que até então encarnava um ideal para si, prescindindo do outro, buscará neste modelo ideal externo os parâmetros para seu júbilo narcísico. Refletindo metaforicamente, é como se Narciso, ensimesmado em seu reflexo no lago, ao invés de sucumbir a esse auto enamoramento, afogando-se, conseguisse enxergar alhures uma versão outra de si, saindo em busca dessa imagem ideal construída no horizonte das relações.

Em sua discussão sobre as massas, Freud (1921/1996) se deterá na análise dos grupos tanto em suas relações com o líder, como com o outro. Nela, o psicanalista nos aponta que por meio do mecanismo de identificação, o grupo assume uma coesão configurada como uma extensão narcísica, sustentada por um ideal de eu encarnado no líder.

Nesse texto, Freud amplia a discussão sobre o narcisismo das pequenas diferenças iniciada em "O Tabu da Virgindade" (1917/1996), onde, partindo da concepção estruturante do narcisismo e, por conseguinte, de seu papel central nas relações estabelecidas em sociedade entre o eu e o outro, o psicanalista comenta sobre alguns dispositivos de regulação sexual e divisões de gênero ao longo da história, 
destacando os tabus cujos objetivos eram evitar o encontro com a diferença sexual localizada no órgão genital feminino - pequena diferença - e, consequentemente, com a castração. Textualmente, Freud (1917/1996, p. 209) expõe: "A rejeição narcísica das mulheres pelos homens está ligada ao complexo de castração e sua influência na formação da opinião sobre elas".

Partindo dessa discussão da pequena diferença inscrita no real do corpo, cujos efeitos, em diferentes tempos, ocorrem em uma estruturação falocêntrica do socius, Freud ao longo de outros textos nos permitirá perceber como as pequenas diferenças vão se articulando a discursos diversos e formas de organizações grupais, fomentando uniões e desuniões. Na lógica dos grupos, a pequena diferença está do lado de fora e emerge como um potencial perigo por mostrar que o ideal de eu não pode se coadunar ao eu ideal. Na iminência desta ameaça narcísica, Freud (1921/1996, 1930/1996) encontrará a raiz das animosidades, exclusões, guerras e do nosso permanente malestar.

No esteio de Lacan, Caterina Koltai (2000), atenta para os fundamentos de ordem imaginária e simbólica essenciais para a compreensão das experiências grupais. Ela nos fala da incidência do simbólico sobre o imaginário, elucidando que a percepção da diferença se dá por meio de uma amarração dos registros. Faz-se necessário um discurso, um universo simbólico que aponte as semelhanças e diferenças, estabeleça pactos de convivência, institua líderes e laços sociais.

O simbólico, com sua estrutura significante, é aquilo que vem emoldurar um quadro, dar contorno e valor à imagem, limitando a realidade a certas marcas, medidas e atuando como um navegador das paixões. Já o real, trata-se do que persiste como não-simbolizável, associa-se ao mal-estar, ao que não foi elaborado em nossa história de disputas, interrogando-nos. Žižek (1996), nesse sentido, nos fala que a realidade nunca é ela mesma, mas uma estrutura ficcional, e aquilo que permanece como resto, existindo fora dessa ficção, é o real.

Eu seu texto "Moisés e o Monoteísmo", Freud (1939/1996) reflete sobre as razões psíquicas do antissemitismo. Em suas investigações sobre o líder hebreu e as fundações do pensamento judaico-cristão, ele nos sinaliza que a representação inconsciente da circuncisão está associada à visão da castração, razão pela qual, o povo judeu, historicamente, suscitou tantas reações de ódio e aversão. Nessa conjectura freudiana, podemos observar como a incidência do simbólico dimensiona e qualifica uma imagem, gerindo a "pequena diferença". Apropriando-se dessa imagem - 
o pênis circuncidado - cujas associações inconscientes abarcam outras imagens por meio de associações significantes, o discurso antissemita instituiu qualificações, parâmetros de comportamento, convivência, regras, leis e, em última instância, um projeto genocida no nazismo, desqualificando o judeu de seu estatuto humano radicalidade absoluta da diferença.

Lacan (1948/1998) nos fala que o narcisismo possui relação direta com a agressividade e a paranoia. Colocando em prática o exercício freudiano de transpor o individual para o social, podemos aproximar a noção de agressividade da noção de violência - violência que se estabelece tácita e explicitamente, intra e Inter grupalmente, em forma de práticas discursivas como, por exemplo, o racismo e a Igbttfobia (cujo sufixo fobia designa uma aversão ou medo irracional, sentimentos relacionados à paranoia), ou como violência institucionaliza em normas, regras e leis.

Na linha do que nos fala a psicanalista Maria Rita Kehl (2010), estas violências podem ser lidas como expressões de sintomas sociais. Dinâmicas ou expressões da luta de classes que se repetem na nossa história, decorrentes de uma não elaboração do passado e de um apagamento da memória. Mitos, como os da cordialidade e do pacifismo encobrem as marcas violência de nosso passado colonizador, escravagista e as tensões, recorrentemente silenciadas, com nossos opressores e agressores. Ao encontro do que nos fala Kehl, Žižek (1996) pensa o real (lacaniano) em analogia à luta de classes, pois ele retorna como aquilo que não foi simbolizado no campo social e que, como tensão permanente, persiste nos interrogando, demandando escuta e nomeação.

$\mathrm{Na}$ perspectiva de Agamben (2009), articulado ao pensamento de Benjamin, e em interlocução com a psicanálise freudolacaniana, nos propomos a abordar esses sintomas (KEHL, 2010) por um olhar contemporâneo, compreendendo que contemporâneo não é quem coincide com seu tempo, mas quem é capaz de se afastar do presente e observar o que resta do passado o interpelando.

\section{RePETIÇÃo E MEMÓRIA}

Abordar o conceito de repetição em psicanálise implica falar sobre a compulsão à repetição. Formalizado na obra "Além do princípio do prazer" (1920/1996), o conceito encontra-se subjacente em vários escritos freudianos. Em "Recordar, Repetir e Elaborar" (1914/1996), Freud apresenta-nos a repetição como algo que atravessa tanto a experiência clínica, por meio da transferência do paciente com o analista, quanto as relações sociais. O sujeito busca inconscientemente repetir ações, que Freud denomina 
de "transferência do passado esquecido" (p. 166), articuladas a sintomas oriundos de traumas. No trabalho clínico, essa repetição ocorre na transferência com o analista, o qual deve auxiliar o paciente a rememorar aspectos de suas experiências que estejam ligadas a essa compulsão, de modo a propiciar a elaboração do trauma.

Freud (1920/1996), ao analisar a brincadeira de seu neto com o carretel (Fort Da!), aborda a repetição no contexto de uma busca transcendente ao exercício de obtenção de prazer, na medida em que a ação repetitiva comporta uma ambiguidade, prazer - desprazer. Ele associará essa busca à pulsão de morte, evidenciando a tendência do sujeito a regredir a um estágio anterior à vida - estado inanimado.

No vértice da discussão freudiana, Lacan (1963-64/1985) afirma que a repetição vincula-se à busca do objeto perdido - objeto que podemos remontar ao seio materno - primeiro objeto de satisfação pulsional do infans, cujo prazer proporcionado jamais é reencontrado. Na leitura lacaniana, o automatismo da repetição impele o sujeito ao gozo e é na cadeia significante - nos objetos nomeados na cultura - que o sujeito tenta encontrar os objetos de satisfação para a pulsão.

A repetição trata-se da tendência de retornar a um lugar, mas que por transcorrer na cadeia significante, em uma dimensão que antecede e determina o sujeito, à revelia de suas possibilidades, nunca se trata do mesmo lugar. (LACAN, 1963-64/1985). Temos na repetição, portanto dois paradoxos: movimento de prazer-desprazer e de retorno a um mesmo lugar (satisfação, encontro), que nunca é exatamente o mesmo.

No que tange ao aspecto da memória em sua relação com a repetição, Freud (1914/1996) nos falara que as memórias recalcadas ensejam as compulsões sintomáticas. A ausência de palavras capazes de simbolizar as reminiscências emergentes leva o sujeito a atuar. No sentido dessa discussão, Kehl (2010, p. 124) comenta sobre o sintoma social: "O sintoma social se manifesta por meio de práticas e discursos que se automatizam, independentes das estruturas psíquicas singulares de cada um de seus agentes. Assim como ocorre quando o sintoma individual se torna crônico, sem tratamento, também o sintoma social tende a se agravar com o passar do tempo.” E complementa: “(...) se o trauma, por sua própria definição de real não simbolizado, produz efeitos sintomáticos de repetição, as tentativas de esquecer os eventos traumáticos coletivos resultam em sintoma social” (KEHL, p. 126). 
No sentido do que a psicanalista argumenta² e considerando o valor da memória para a elaboração do trauma (FREUD, 1914/1996), podemos refletir, também no esteio de Walter Benjamin, nos efeitos de uma memória social, que é simultaneamente individual e coletiva e, podemos pensar, de maneira análoga ao estatuto do inconsciente: trans-individual (LACAN, 1953/1998).

Advogando a favor do resgate das memórias "recalcadas" e contrapondo-se às memórias institucionalizadas, Benjamin (1940/1987) nos alerta para as armadilhas de uma visão totalizante da história. "Articular historicamente o passado não significa conhecê-lo 'como ele de fato foi'. Significa apropriar-se de uma reminiscência” (p. 224). Essa sentença aproxima-se da concepção freudiana de rememoração, pois rememorar não é trazer à tona uma memória em sua exatidão, mas apropriar-se singularmente dela, ou seja, operar com a memória no modo como ela se constitui nas fantasias e articula-se ao sintoma.

Benjamin (1936/1987) endossa que: “(...) a memória é a mais épica de todas as faculdades. Somente uma memória abrangente permite à poesia épica apropriar-se do curso das coisas, por um lado, e resignar-se por outro lado, com o desaparecimento dessas coisas, com o poder da morte" (p. 210).

Nesse sentido, podemos pensar na memória, por meio da narrativa - e aqui talvez possamos traçar um paralelo com a associação livre em análise - como algo capaz de provocar movimentos, simbolizar os inelutáveis processos de vida e morte, presença e ausência, diferença e repetição. Na poesia, encontramos o poder das palavras em colocar no jogo simbólico os não-ditos, reestruturando sentidos e relações, elaborando.

\section{Feridas Abertas e Antagonismos: O Que Resta E Se Repete No Brasil}

Os fantasmas de todas as revoluções estranguladas ou traídas, ao longo da torturada história latino-americana, emergem nas novas experiências, assim como os tempos presentes, pressentidos e engendrados pelas contradições do passado. A história é um profeta com o olhar voltado para trás: pelo que foi e contra o que foi, anuncia o que será (GALEANO, 1987, p. 19).

Sustentando uma singularidade na escrita, buscaremos aproximar os conceitos discutidos e operacionalizá-los por meio de uma visão caleidoscópica de nossa história

\footnotetext{
2 Ressaltamos que essa argumentação se coaduna ao seu trabalho na Comissão da Verdade, cujo intuito era investigar os crimes cometidos durante a ditadura civil-militar brasileira, em um trabalho de resgate de memória e tentativa de elaboração do trauma.
} 
- anacrônica, pois passado e presente se intercruzam, interpelando-se mutuamente perscrutando, por meio da atenção flutuante, nossas camadas de memórias e os significantes que as atravessam. Trata-se, ao modo psicanalítico e benjaminiano, de um exercício e uma abordagem sem vistas à neutralidade ou ao resgate dos fatos como eles de fato foram, mas de um ensaio teórico com o intuito de abrir sentidos, caminhos possíveis para a elaboração do que resta e se repete no Brasil.

O Brasil, país de dimensões continentais e múltiplas possibilidades de encontros e constituições, é tecido pelas pequenas diferenças. Gradativas e permeáveis, essas diferenças se evidenciam nas cores, sons, ritmos de corpos e territórios. Seu nome, assim como o de Narciso, emana da natureza e agiganta-se por ela. Sua identidade é marcada pelo falicismo da floresta imponente e a castração de sua árvore homônima pau-brasil. Sua cultura se assenta no real do genocídio indígena, da barbárie escravocrata, dos golpes de estado e das ditaduras.

Suas rixas e divisões são as mais variadas, tecendo um quatro de animosidades internas e externas. Freud (1921/1996,1930/1996), ao discutir questões do narcisismo das pequenas diferenças, já falara que comunidades de territórios adjacentes e mutuamente relacionadas, se empenham em rivalidades. Nesta discussão, o autor cita as rixas entre portugueses e espanhóis, que podemos apontar como em repetição no nosso continente de veias abertas, entre os lusófonos brasileiros e os hispanófonos argentinos.

$\mathrm{Na}$ cadência da camada social que sobe e desce os morros, os brasileiros se veem refletidos no senhor e no escravo, no proprietário e no expropriado. É senhorzinho, é capitão do mato, mas também é o corpo mutilado de Zumbi e Dandara dos Palmares. Não à toa, nossas figuras folclóricas - Saci, mula-sem-cabeça - trazem a castração no real do corpo.

No Brasil contemporâneo, midiático e globalizado, a violência é naturalizada para que o significante segurança se mantenha monetizado. Presídios de segurança máxima e condomínios (de segurança máxima) são erguidos para as classes médias e altas sentirem-se protegidas dos diferentes - via de regra, seres de pele negra como o Saci. A sociedade do consumo se expande orientada pela política do gozo, enunciada na mídia global entre novelas, comerciais, telejornais e fomentando novas diferenças: os consumidores e os sem (sem-terra, sem-teto, sem emprego).

Joel Birman, no livro "Cadernos sobre o Mal” (2009, p. 245), comenta: “(...) hoje no Brasil há um clima de alta agressividade que permeia as relações humanas e se 
manifesta por múltiplos signos. A violência, desdobrada na criminalidade com níveis inéditos de crueldade, evidencia nossa degradação simbólica".

Onde faltam palavras, onde não ocorre o resgate e reconstituição da memória, sobram atos. Assim, a incapacidade de nomear e aceitar as diferenças, de passar da repetição à elaboração dos traumas constituintes de nossa sociedade, leva-nos ao excesso e à barbárie. Como o psicanalista Joel Birman (2017) comenta na palestra "Precisamos falar sobre o fascismo": "O Estado é genocida porque a polícia é treinada para matar. O outro é animalizado. Na perspectiva de Agamben, a vida qualificada transformada em vida nua".

Ele nos fala ainda de um episódio recente da história política brasileira como metáfora para o fascismo: a homenagem de Bolsonaro ao Coronel Ustra durante a votação de impeachment da ex-presidente Dilma Rousseff. Na concepção do psicanalista, a ode à tortura compõe uma discursividade e um gesto de desumanização do outro, empuxo a uma significação animalesca do humano, posicionando-o em um lugar de passibilidade aos maus-tratos e ao abate. (Birman, 2017).

Nesse sentido, Kehl (2010) comenta:

\begin{abstract}
O "esquecimento" da tortura produz, a meu ver, a naturalização da violência como grave sintoma social no Brasil. Soube, pelo professor Paulo Arantes, que a polícia brasileira é a única na América Latina que comete mais assassinatos e crimes de tortura na atualidade do que durante o período da ditadura militar. A impunidade não produz apenas a repetição da barbárie: tende a provocar uma sinistra escalada de práticas abusivas por parte dos poderes públicos, que deveriam proteger os cidadãos e garantir a paz. (KEHL, 2010 p. 24).
\end{abstract}

Sabemos que a repetição não é idêntica (Lacan, 1963-64/1985), o que muitas vezes obnubila nossa capacidade de percebê-la em cena no agora. No que Birman (2017) e Kehl (2010) nos trazem, evidenciam-se os traços do passado na atualidade: a violência perpetrada pela ditadura, impune e esquecida, repete-se de maneira diferente, agora sob um verniz democrático, por instituições e agentes de Estado em gestualidades e modus operandis fascistas no cotidiano.

Na letra de sua canção "Podres Poderes", Caetano Veloso (1984) questiona: "Será que nunca faremos, senão confirmar, a incompetência da América católica que sempre precisará de ridículos tiranos.”. Esse trecho da canção nos dá a ver elementos da nossa colonização vinculada ao autoritarismo de instituições autointituladas cristãs. Ela nos interpela e nos faz refletir sobre as "massas narcísicas" brasileiras, 
dependentes e demandantes de figuras religiosas, messiânicas, supostos restauradores da ordem e da paz.

Em um quadro de tempos heterogêneos, vemos políticos, em nome deus, da família e dos bons costumes, cooptarem os narcisismos com performances repletas de gestos e sentidos prêt-a-porter. O teatro burlesco dos púlpitos, agressivo e politicamente incorreto, salvaguarda o boi, a bala, a bíblia, legisla sobre os corpos, os modos de gozo e institui discursivamente as diferenças que demarcam o direito ou não à existência.

Tendo como base as discussões de Freud (1917/1996) acerca da relação de gênero em "Tabu da Virgindade", algumas problematizações acerca dessas relações no Brasil podem ser trazidas à tona. Salários desiguais, altos índices de estupro, discursos misóginos, negação do direito ao aborto, salvo em casos específicos, e a transfobia denotam a assimetria entre os gêneros e a persistência do poder discursivo masculino. De acordo com matéria do El País Brasil (Avendaño, 2017):

E a realidade é que, desde 2015, o Brasil é o país que mais mata transexuais no mundo. Embora essa triste honra se deva, em parte, ao enorme tamanho de seu território e sua população, o fato alarmante é que cada vez se mata mais. Segundo o Grupo Gay da Bahia, em 2016 foram assassinados, 144, 22\% mais que em 2015 mas menos que em 2017: até agora, foram 183 homicídios. Um recorde histórico.

No século XVII, os significantes do racismo instituídos em uma racionalidade escravocrata, mataram Dandara dos Palmares. No século XXI, mata-se a transexual Dandara dos Santos. Da pequena diferença demarcada pelo significante da cor ao significante da diferença sexual - diferença que agora aparece em um corpo que escapa à normatização cis e heterossexual. Passando pelos dispositivos sociais forjados na história, como o supracitado tabu da virgindade, assiste-se na contemporaneidade tentativas de suprimir a diferença sexual dos corpos. Dentre esses, as mais visadas são as que interrogam as categorias biopolíticas hegemônicas; corpos que desorganizam a partilha do poder perpassada pelo imaginário fálico e evidenciam a lógica não-toda.

"O dom de despertar no passado as centelhas da esperança é privilégio exclusivo do historiador convencido de que também os mortos não estarão em segurança se o inimigo vencer. E esse inimigo não tem cessado de vencer". (BENJAMIN, 1940/1987, p. 224-225). O pensamento de Benjamin é messiânico, atravessado pelo teologismo, mas sua perspectiva não se coaduna às das instituições religiosas. Para ele, a salvação dos mortos ocorre em um movimento dialético, entre 
imagens do presente e do passado - em sua diferença antitética que abarca a repetição - na possibilidade de diálogo entre vivos e mortos que possam abrir brechas para o futuro.

Nos emaranhados do pensamento benjaminiano, podemos apontar no cotidiano brasileiro, a despeito do pujante mal-estar e da fragilidade da linguagem diante das animalidades, caminhos possíveis para a redenção. Conseguimos, por exemplo, transformar a dor da injustiça em poesia musical - os sambas, canções regionais e folclóricas louvam os corpos e territórios nacionais, suas curvas, marcas, cores e dores. Como nos fala Jorge Forbes (2016) em "Você quer o que deseja?": "(...) a régua e o compasso da vida brasileira vêm de sua música, e não da engenharia" (p. 55).

Demonstramos que somos capazes de transformar sintomas sociais em arte, em linguagens e ações não automatizadas, permitindo-nos resgatar e ressignificar imagens, reinventar modos de convivência contrapostos ao fascismo. A arte, em seu caráter indissociável da política e, de modo geral, da vida, nos permite reinventar passado e presente, romper com os automatismos propulsionados pelas visões enrijecidas do idêntico e da diferença, mantenedoras de nossas feridas.

O artista Cildo Meirelles, no Projeto Cédula, realizado nos anos 70, carimbou em notas de cruzeiro a pergunta: "Quem matou Herzog?". Recentemente, a ação artística se repete com a questão "Quem matou Mariele?", carimbada em notas de real (BALBI, 2019). Vemos que ao repetir sua indagação política, o artista nos permite ver o que se repete em nossa história, evidenciando nossos sintomas sociais - violência e resistência, diferença como mote para vida e morte. 


\section{CONSIDERAÇõEs FinaIS}

Em "Análise terminável e interminável" (1937/1975), Freud argumenta que a análise é incapaz de impedir a repetição e, por conseguinte, levar à cura tal como é proposto por alguns saberes médicos. A cura se dá no a posteriori, na dimensão da (im)possibilidade; e a repetição, para além do flagrante do sintoma, caracteriza-se por ser constituinte do sujeito, instituindo-o no campo do desejo e das relações.

A repetição é não idêntica, portanto, carrega um germe da mudança, da possibilidade de quebrar cenas cristalizadas pelo sintoma por meio de novas palavras, sentidos e sem-sentidos. Assim, podemos considerar o resgate da memória no âmbito social - imagens e vozes do passado recalcadas - como fomentadoras de brechas nos discursos totalizantes do presente.

A memória em elaboração trata-se de uma tentativa de diálogo entre tempos, interpela aquilo que pulsa, mas cuja pulsação pode estar tanto a favor do sofrimento humano - miséria neurótica e miséria humana nas dimensões da desigualdade, opressão e violências outras - quanto como motor de modos de viver, se relacionar, gozar e desejar mais alinhados a um campo político democrático, onde a palavra possa circular.

As pequenas diferenças tensionam as relações humanas, engendram peças de amor e ódio, e na pólis, podem servir tanto à união, quanto à segregação, razão da civilização e da barbárie. São nomeadas, expandidas ou aproximadas pelo simbólico, e pelo real, revelam-se insustentáveis em certa medida. Historicamente, busca-se sustentar um discurso de identidade nacional brasileira, resgatando em fantasmas não elaborados de outros tempos, o verdadeiro brasileiro e o outro - 0 inimigo, o estrangeiro -, mas o Brasil não tem fórmulas prontas (FORBES, 2016), sua imagem é mutante, seu reflexo é difuso, é outro, são outros, uma roda viva. Pela invocação de nossas memórias, contra a anestesia e o esquecimento, podemos manter vivas as diferenças, inserindo-as em espaços possíveis de convivência e de expressões do desejo. 


\section{REFERÊNCIAS}

AGAMBEN, G. O que é contemporâneo? e outros ensaios. Chapecó: Argos, 2009.

AVENDAÑO, T, C. Brasil é o céu e o inferno para os transexuais, dez. 2019. Disponível em: https://brasil.elpais.com/brasil/2017/12/30/politica/1514633797_328738.html. Acesso em: nov.2019, 14:00min.

BALBI, C. Cildo Meirelles se diz com sangue nos olhos décadas após a última mostra de peso, set. 2019. Disponível em: https://www1.folha.uol.com.br/ilustrada/2019/09/cildo-meireles-sediz-com-sangue-nos-olhos-decadas-apos-ultima-mostra-de-peso.shtml. Acesso em: nov. 2019, 16:20min.

BENJAMIN, W. O narrador: Considerações sobre a obra de Nikolai Leskov. In Magia e técnica, arte e política: Ensaios sobre literatura e história da cultura. 3. ed. São Paulo: Editora Brasiliense, 1987.

BENJAMIN, W. Sobre o conceito de história. In Magia e técnica: arte e política: Ensaios sobre literatura e história da cultura 3.ed. São Paulo: Editora Brasiliense, 1987.

BIRMAN, J. Cadernos do Mal. Rio de Janeiro: Record, 2009.

BIRMAN, J. Precisamos falar sobre o fascismo (Vídeo), abr. 2017. Disponível em: https://www.youtube.com/watch?v=IKi3-32PIjM. Acesso em: out. 2019, 16:00 min.

FORBES, J. Você quer o que deseja? Barueri: Manole, 2016.

FREUD, S. (1937). Análise terminável e interminável. In: Freud, S. Obras Psicológicas Completas de Sigmund Freud. Vol. 23. Rio de Janeiro: Imago, 1975.

FREUD, S. (1914). Recordar, repetir e elaborar (Novas recomendações sobre a técnica da psicanálise II). In Edição Standard Brasileira das Obras Psicológicas Completas. Vol. 12. Rio de Janeiro: Imago, 1996.

FREUD, S. (1917). O tabu da virgindade (Contribuições à psicologia do amor III). In Edição Standard Brasileira das Obras Psicológicas Completas. Vol. 11. Rio de Janeiro: Imago, 1996.

FREUD, S. (1920) Além do princípio do prazer. In Edição Standard Brasileira das Obras Psicológicas Completas. Vol. 18. Rio de Janeiro: Imago, 1996.

FREUD, S. (1921). Psicologia de grupo e análise do ego. In Edição Standard Brasileira das Obras Psicológicas Completas. Vol. 18. Rio de Janeiro: Imago, 1996.

FREUD, S. (1930). O mal-estar na civilização. In Edição Standard Brasileira das Obras Psicológicas Completas. Vol. 21. Rio de Janeiro: Imago, 1996.

FREUD, S. (1939). Moisés e o monoteísmo. In Edição Standard Brasileira das Obras Psicológicas Completas. Vol. 23. Rio de Janeiro: Imago, 1996. 
FREUD, S. (1914). Introdução ao narcisismo. In Introdução ao narcisismo, ensaios de metapsicologia e outros textos: Obras Completas. Volume 12. São Paulo: Companhia das Letras, 2010.

FUKS, B. A extimidade própria à psicanálise. Trivium - Estudos Interdisciplinares, v. 8, n. 1, p. 110-111, jul. 2016. Disponível em: http://pepsic.bvsalud.org/scielo.php?script=sci_arttext\&pid=S2176-48912016000100013. Acesso em nov. 2019, $13 \mathrm{~h} 40 \mathrm{~min}$.

GAGNEBIN, J. M. Limiar, aura e rememoração. São Paulo: editora 34, 2014.

GALEANO, E. Veias abertas da América Latina 24. ed. Rio de Janeiro: Paz e Terra, 1987.

KEHL. M. R. Tortura e sintoma social. In: SAFATLE, Vladimir (Org.), o que resta da ditadura: a exceção brasileira. São Paulo: Boitempo, 2010.

KOLTAI, C. Política e psicanálise: o estrangeiro. São Paulo: Escuta, 2000.

LACAN, J. (1963-64). O seminário - livro 11 - os quatro conceitos fundamentais de psicanálise (2a ed.). Rio de Janeiro: Zahar, 1985.

LACAN, J. (1953-54). O Seminário - livro 1 - os escritos técnicos de Freud. Rio de Janeiro: Editora Zahar, 1986.

LACAN, J. (1956-57). O Seminário - livro 4 - a relação de objeto. Rio de Janeiro: Editora Zahar, 1995.

LACAN, J. (1948). A agressividade em psicanálise. In Escritos. Rio de Janeiro: Jorge Zahar, 1998.

LACAN, J. (1949). O estádio do espelho como formador da função do eu. In Escritos. Rio de Janeiro: Jorge Zahar, 1998.

LACAN, J. (1953). Função e campo da fala e da linguagem em psicanálise. In Escritos. Rio de Janeiro: Jorge Zahar, 1998.

LACAN, J. (1968-69). O seminário - livro 16 - de um Outro ao outro. Rio de Janeiro: Zahar, 2008.

VELOSO, C. Podres Poderes. Brasil: Philip Records, 1984.

ŽIŽEK, S. Um mapa da ideologia. Rio de Janeiro: Contraponto, 1996. 


\title{
BRAZILIAN WOUNDS: NARCISISMO OF SMALL DIFERENCES, REPETITION AND MEMORY
}

\begin{abstract}
This article aims to reflect about the freudian concept of narcissism of small differences thought from the binding of lacanian registers of real, symbolic and imaginary, and its incidence in brazilian social relations at different times. It starts from the discussion of the concept in psychoanalytic theory, and then, dialoguing with theorists such as Walter Benjamin and Giorgio Agamben, reflect on the repetition, as well as on the relevance of memory for the perception of our social symptoms. It discusses how some discourses appropriate the image of differences to perpetrate and rescue logic of oppression, inequality and how the rescue of memory, articulated with a possibility of elaboration, can give rise to different ways of relating in the polis and deal with the differences.
\end{abstract}

KEYWORDS: Narcissism. Difference. Repetition. Memory. Symptom 


\section{PLAIES BRESILIENNES: NARCISISME DE PETITES DIFFÉRENCES, RÉPETITION ET MÉMOIRE}

\section{RÉSUMÉ}

Cet article vise à réfléchir au concept freudien de narcissisme des petites différences, issu des registres lacaniens de réels, symboliques et imaginaires, et de son impact sur les relations sociales brésiliennes à différentes époques. Il commence par la discussion du concept dans la théorie psychanalytique, puis, en collaboration avec des théoriciens tels que Walter Benjamin et Giorgio Agamben, réfléchit à la répétition, ainsi qu'à la pertinence de la mémoire pour la perception de nos symptômes sociaux. II discute de la manière dont certains discours s'approprient l'image des différences pour perpétrer et sauver la logique de l'oppression, des inégalités et comment le sauvetage de la mémoire, articulé avec une possibilité d'élaboration, peut donner lieu à différentes manières de relier dans la polis et faire face aux différences.

MotS-CLÉs: narcissisme. Différence. Répétition. Mémoire. Symptôme. 
RECEBIDO EM 25/11/2019

APROVADO EM 22/06/2020

(C) 2020 Psicanálise \& Barroco em revista

http://www.seer.unirio.br/index.php/psicanalise-barroco/index revista@psicanaliseebarroco.pro.br

Programa de Pós-Graduação em Memória Social — UNIRIO

Memória, Subjetividade e Criação

www.memoriasocial.pro.br/proposta-area.php 